\title{
FILOSOFIA DO DIÁLOGO: APROXIMAÇÕES ENTRE HANNAH ARENDT E EMMANUEL LÉVINAS
}

\author{
Renato Somberg Pfeffer ${ }^{1}$
}

\begin{abstract}
Resumo:
As obras de Hannah Arendt e de Emmanuel Lévinas não podem ser dissociadas dos eventos catastróficos que marcaram o século XX, em especial, a Segunda Guerra mundial. Ambos vivenciaram a crise do da Civilização Europeia do século passado que havia mergulhado no self ao invés de valorizar a pluralidade. O objetivo do presente artigo é analisar natureza crítica da obra desses pensadores acerca do caráter ontológico e contemplativo da Filosofia Ocidental e como buscaram uma alternativa para o adoecimento do humanismo ocidental por meio de uma Filosofia do diálogo. Para o desenvolvimento desse artigo utilizou-se de uma metodologia hermenêutica e comparativa recorrendo a uma revisão bibliográfica dos pensadores supracitados e de outros que se dedicaram ao tema. A título de conclusão é possível inferir que a Filosofia ontológica que predominou desde o início dos tempos modernos no ocidente desencadeou uma racionalidade desmedida e autossuficiente que reflete e é refletida pela sociedade contemporânea alicerçada no isolamento, na competição, no consumismo e na indiferença. Sujeito apenas aos limites impostos pela própria consciência, o homem moderno se fechou em si mesmo sacrificando a transcendência. Criticando essa ética centrada no eu e indo além da Filosofia do diálogo de Martin Buber, Arendt e Lévinaspropõem uma perspectiva dialógica de pensar o si mesmo a partir e com o outro na busca de uma sociedade justa, assentada na pluralidade e na paz. Depositando uma fé profunda na capacidade humana de agir e realizar o milagre do renascimento, esses filósofos defendem que esse seria o sentido da própria existência.
\end{abstract}

Palavras-chave: Hanna Arendt. Condição humana. Emmanuel Lévinas. Face-a-face. Filosofia do diálogo.

\section{DIALOGUE PHILOSOPHY: APPROCHESBETWEENHANNAH ARENDTAND EMMANUEL LÉVINAS}

\begin{abstract}
:
The works of Hannah Arendt and Emmanuel Lévinas cannot be dissociated from the tragic events that marked the 20th century, in particular, the Second World War. Both experienced the crisis of the European Civilization of the last century, immersed into the self instead of valuing plurality. The purpose of this article is to analyze the critical nature of the work of these thinkers about the ontological and contemplative character of Western philosophy and how they sought an alternative for the illness of western humanism through a dialog philosophy. For the development of this article, a hermeneutic and comparative methodology was used through bibliographical review of the above mentioned thinkers and other who dedicated themselves to the theme. As a conclusion, it is possible to infer that the ontological philosophy that prevailed from the beginning of modern times in the West unleashed an excessive and self-sufficient rationality that reflects and is reflected by contemporary society itself based on isolation, competition, consumerism and indifference. Subject only to the limits imposed by his own conscience, modern man closed himself by sacrificing transcendence. Criticizing selfcentered ethics and overcoming Martin Buber's philosophy of dialogue,Arendt and Lévinas propose a dialogical perspective of thinking oneself from and with the other in the pursuit of a just society, based on plurality and peace. Depositing a deep faith in the human capacity to act and perform the miracle of rebirth, these philosophers argue that this would be the meaning of existence itself.
\end{abstract}

Keywords:Hanna Arendt. Human condition. Emmanuel Lévinas. Face-to-face. Dialogue Philosophy.

${ }^{1}$ Doutor em Filosofia, Tecnologia e Sociedade pela Universidade Complutense de Madri (título revalidado pela UFJF); Mestre em Sociologia pela UFMG, Pós-graduado em História do Brasil pela Pucminas; Graduado em Comunicação Social pela UFMG e História pela FAFI-BH. Professor titular do Ibmec-MG e Pesquisador da Fundação João Pinheiro de Minas Gerais. E-mail: renato.pfeffer@ fjp.mg.gov.br 


\section{Introdução}

As obras da alemã Hannah Arendt (1906-1975) e do lituano Emmanuel Lévinas (1905-1995), ambos judeus, não podem ser dissociadas dos eventos que marcaram o século XX, em especial, a Segunda Guerra Mundial. Eles foram críticos do caráter ontológico econtemplativo da Filosofia Ocidental e vivenciaram a crise da Civilização Europeia do século passado que havia mergulhado no self ao invés de valorizar a pluralidade humana. Arendt e Lévinas buscaram uma alternativa para o adoecimento do serhumano por meio de uma Filosofia vinculada a uma abordagem dialógica que valorizasse a condição humana de pluralidade, ou seja, "ao fato que os homens, e não o Homem, vivem na Terra e habitam o mundo" (Arendt, 2017, p. 15).Essa Filosofia do diálogo seria uma exigência para a humanidade devido ao fato de sermos todos iguais em nossa humanidade e, ao mesmo tempo, diferentesde "qualquer pessoa que tenha existido, exista ou venha a existir"(Arendt, 2017, p. 16).

O objetivo do presente artigo é discutir a temática arendtiana da ação - a mais elevada das atividades humanas - aproximando-a do conceito de face-a-face de Lévinas recorrendo a uma metodologia hermenêutica e comparativa, o que foi possível mediante uma revisão bibliográfica dos pensadores supracitados e de outros que se dedicaram ao tema. As duas primeiras seções do artigo são dedicadas à Hannah Arendt, sendo a primeira um esboço de suas ideias com ênfase na crítica ao caráter contemplativo da Filosofia Ocidental e a segunda expondo sua concepção acerca da irreversibilidade e imprevisibilidade da ação e do poder de perdoar contidas no livro "A condição humana" (Arendt, 2017). Na terceiraseção é exposto o entendimento de Lévinas referente ao humanismo e ao pluralismo, além de alguns de seus apontamentos críticos em relação às ideias de Martin Buber (1878-1965) e Heidegger (1889-1976). A título de conclusão é realizado no último apartado uma aproximação das criticas de Arendt e Lévinas à Filosofia Ocidental e a defesada complementariedade entre a temática da ação e o conceito de face-a-facenesses pensadores.

\section{Hannah Arendt e a crítica à Filosofia contemplativa}

A teoria política de Arendt recebeu grande influência intelectual, ainda como estudante, de Heidegger, de quem acabou se afastando ainda antes da década de 1930. Do filósofo, Arendt preservou em suas obras a ideia de que a linguagem tinha a função de preservação e revelação (Lafer, 1979). A origem de sua Fenomenologia que tem como princípio a busca de significado para as palavras expressas em eventos fáticos, em especial,

\begin{tabular}{|c|c|c|c|c|}
\hline Rovista Dialectus & Ano 5 & n.13 & Agosto - Dezembro 2018 & p. $210-227$ \\
\hline
\end{tabular}


“de termos-chave de fenômenos políticos, como, por exemplo, violência, força, revolução e liberdade" (Machado, 2013, p. 82), pode ser encontrada na manutenção desses conceitos heideggerianos. A tentativa de elaborar reflexões a partir de fatos concretos, porém, afastou Arendt da tradição contemplativa dos filósofos ocidentais que, segundo ela, alterariam a realidade ao separar sujeito e objeto. No caso da política, especificamente, essa separação provocaria uma distorção de percepção do real.

Influenciada por Karl Theodor Jaspers (1883-1969), orientador de sua tese de Doutorado, Arendt defende que a Filosofia é uma troca comunicativa entre sujeitos iguais que buscam compreender a existência. A existência e a comunicação são imbrincadas porque a ação que determina a existência ocorre na atividade comunicativa com os outros, ou seja, ela não é uma atividade interior (Barbosa, 2017). Essa dimensão relacional e comunicacional da existência é destacada por ela quando diferencia a Filosofia de Jaspers e Heidegger:

\begin{abstract}
A existência em si, por sua própria natureza, nunca é isolada. Existe apenas na comunicação e na consciência da existência dos outros. Nossos semelhantes não são (como em Heidegger) um elemento da existência que, embora estruturalmente necessário, é ao mesmo tempo um impedimento ao Ser do Eu. Muito pelo contrário, a existência só pode se desenvolver na vida compartilhada dos seres humanos que habitam num mundo dado, comum a todos eles. No conceito de comunicação encontra-se um novo conceito de humanidade, cuja abordagem, mesmo ainda não plenamente desenvolvida, postula a comunicação como a premissa para a existência do homem... Os seres humanos vivem e agem entre si; assim procedendo, não perseguem o fantasma do Ser, nem vivem na ilusão arrogante de constituírem o próprio Ser (Arendt, 2008a, p. 186).
\end{abstract}

Para Arendt, o aspecto positivo do conceito de comunicação de Jaspers está no fato de enfatizar sua ocorrência entre homens que criam um espaço de revelação ao vincularse uns aos outros. Inicialmente, ela aponta um aspecto negativo do conceito, pois esse dizia respeito à comunicação entendida como um diálogo pessoal, ao invés da experiência de pluralidade de visões de mundo que ocorre no âmbito da política (Barbosa, 2017). Porém, Arendt acaba abandonando "sua crítica à dimensão da singularidade do diálogo comunicativo passando a sublinhar que a filosofia comunicativa de Jaspers não é uma da filosofia do homem, do indivíduo singular, mas uma filosofia da pluralidade humana" (Barbosa, 2017, p. 33). Jaspers teria sido, portanto, o "primeiro e o único filósofo que sempre protestou contra a solidão" (Arendt, 1987, p. 86).

As preocupações com as questões judaicas em Arendt, sejam sobre o sionismo ou da oposição ao nacional-socialismo na Alemanha, passaram a tomar uma dimensão cosmopolita na década de 1930 quando ela passa a discutir temáticas como revolução,

\begin{tabular}{|l|l|l|l|l|}
\hline Gonista Dialectus & Ano 5 & n.13 & Agosto - Dezembro 2018 & p. $210-227$ \\
\hline
\end{tabular}


resistência, conselhos populares e tradição revolucionária (Lafer, 1979). Anos depois e derivadas dessas reflexões, a filósofa publica os livros "Sobre a Revolução" (1963) e "Sobre a violência" (1969), o primeiro versando sobre a diferença entre liberdade e libertação das necessidades materiais da vida, o segundo sobre a ação como recurso proveniente do diálogo entre homens livres. Também na década de 1960, ela publica o livro "Eichmann em Jerusalém" (1963) denunciando a banalidade do mal

(i) do próprio Eichmann, visto como homem comum apesar de ter cometido uma grande atrocidade; (ii) do processo que era utilizado por Israel como instrumento a fim de se legitimar como Estado; (iii) da própria Alemanha, que pregava a excepcionalidade do mal perpetrado pelo nazismo (Machado, 2013, p. 83).

Arendt já havia publicado em 1951 o livro "As origens do totalitarismo" caracterizando o Regime Nacional Socialista alemão (1933-1945) como uma forma inteiramente diferente das formas tradicionais de poder pessoal: a tirania, o despotismo e a ditadura. O totalitarismo teria engendrado uma sociedade marcada pela multidão de indivíduos iguais, pela substituição dos partidos políticos por movimentos de massa, por um regime que possuía ampla ingerência na vida privada e onde o poder deslocava-se para a polícia (Machado, 2013).

Entre o livro que lhe rendeu notoriedade ("Origens do Totalitarismo") e os três livros supracitados publicados na década de 1960, e deixando de lado outras produções significantes, está a obra que mais diretamente interessa ao presente artigo: "A condição humana" (1958). Partindo da concepção de descartabilidade dos seres humanos - discutida na sua análise sobre o Totalitarismo - Arendt reflete a possibilidade do amor mundi, o amor no mundo, conceito esse derivado do pensamento de Santo Agostinho (Arendt, 1997).Diferentemente do pensamento agostiniano, porém, há uma vinculação desse conceito à elucidação do âmbito da política. Como dito anteriormente, a pensadora criticava a Filosofia meramente contemplativa o que provocará uma mutação no conceito proposto por Agostinho de amor mundi.

O distanciamento da autora da Filosofia de inspiração cristã e sua aproximação com a experiência política greco-romana ocorreu a partir do início dos anos cinquenta (Duarte, 2003). Apesar desse distanciamento, é inspirada em Agostinho que Arendt buscará a ideia da capacidade humana de buscar novos começos. No pensador cristão, ela encontra o vínculo entre natalidade humana, a ação (que seria a capacidade de dar início a algo inteiramente imprevisível) e a liberdade. Sendo assim, os novos começos na história existem

\begin{tabular}{|c|c|c|c|c|}
\hline Rovista Dialectus & Ano 5 & n.13 & Agosto - Dezembro 2018 & p. $210-227$ \\
\hline
\end{tabular}


devido à condição humana de natalidade: "como a ação é a atividade política por excelência, a natalidade, e não a mortalidade, pode constituir a categoria central do pensamento político, em contraposição ao metafísico" (Arendt, 2017, p. 17).

Deixando em um segundo plano as implicações teológicas, Arendt indica um vínculo entre ação e liberdade no campo da política. Por ser uma capacidade humana, a liberdade passa existir com o advento dos homens que vão agir e falar no mundo. Por conseguinte, governos que eliminarem a participação plural no espaço público colocam em risco a liberdade humana. A esfera pública e sua durabilidade, portanto, são fundamentais para o amor mundi.

Posto que a autora não explicita o que vem a ser esse amor, investiga-se a noção do amormundi, recorrendo ao conjunto de suas reflexões. Entende-se que, se o mundo é o lugar das histórias humanas no qual podemos estabelecer relações e nos revelar como pessoas, o amor a ele é uma resposta à destruição totalitária desse espaço humano e ao não-mundo da sociedade moderna organizada em torno do processo vital de produção e consumo (Almeida, 2009, p.7).

O advento dos Regimes Totalitários trouxe consigo a recusa do desejo de um homem superar os demais em atos e palavras, pois defendia a igualdade absoluta entre os cidadãos e subordinava a atividade política à atividade econômica. A liberdade e a ação se submeteram à necessidade e a violência obscurecendo a potencialidade do âmbito político. Hannah Arendt discutiu esse obscurecimento da liberdade e a possibilidade de superá-lo por intermédio de laços que unissem a participação política à liberdade. Ela percebia em determinadas manifestações políticas uma sinal, ainda que fugaz, da restituição do político. As Revoluções e os movimentos políticos de resistência à opressão aparecem em seu pensamento como fenômenos de esperança para a liberdade. Em um momento histórico em que as propriedades da ação política e os princípios que regem o espaço público estão em vias de desaparecer sob o peso do trabalho, das burocracias, dos lobbies privados, Arendt traz a tona o conceito de ética de responsabilidade sobre o mundo público.

Arendt, ao afastar o utilitarismo ("o mal menor"), o pragmatismo ("meios e fins") e um fundamento transcendente (como Deus, inferno, fim supremo) para a ação humana, ela busca manter unidos o sujeito da ação com sua decisão e sua atitude. Isso porque Arendt prioriza a política, a qual ocorre na esfera pública, sem, entretanto, desvalorizar o nível privado, aquele dos interesses, desejos e preferências do indivíduo. Pois, segundo ela, esse é secundário: quando a comunidade está em questão, ela tem prioridade em relação à vida pessoal e privada do indivíduo. Essa ênfase na preservação da pessoa humana. (...). Em Arendt, então, a ética deve permanecer no horizonte humano para indicar os limites às práticas com resultados perigosos ou duvidosos para a humanidade. É nesse sentido que a ética, em Arendt, versa sobre a responsabilidade pelo mundo (SCHIO, 2010, P. 166).

\begin{tabular}{|c|c|c|c|c|}
\hline Rovista Dialectus & Ano 5 & $\mathrm{n} .13$ & Agosto - Dezembro 2018 & p. $210-227$ \\
\hline
\end{tabular}


Patente em suas obras está a retomada do Iluminismo ao perceber nele características essenciais que haviam sido deixadas de ladono século $\mathrm{XX}$, em especial, o humanismo. Inspirada em GottholdEphraimLessing (1729-1781), Arendt identifica a amizade como principal característica do humanismo, pois ela possibilita o diálogo, à busca do entendimento, à possibilidade de um acordo e ao consenso entre os seres humanos. A amizade estabelece laços que unem, promovendo a aceitação de outros pontos de vista e a abertura a outras ideias. O humanista/amigo permite vivenciar a liberdade de pensar por si mesmo e se colocar no lugar do outro tentando entender sua posição. Influenciada também porImmanuel Kant (1724-1904), em especial na "Critica da faculdade do juízo" (1993), Arendt (1996) demonstra que através do entendimento humano saudável é possível tornar o mundo mais humano no encontro dos seres no campo da política. A razão iluminista possibilitaria, dessa maneira, a possibilidade de co-pertencimento dos seres humanos no mundo público onde a igualdade nos interesses comuns são partilhados.

\section{A irreversibilidade e imprevisibilidade da ação e o poder de perdoar}

Em “A condição humana" (2017) são analisadas as atividades comuns entre os homens que compõem a vida activa, ou seja,"a vida humana na medida em que se empenha ativamente em fazer algo" (Arendt, 2017, P. 31). Essas atividades seriam compostas pelas três condições humanas: a vida, a mundanidade e a pluralidade. A primeira referindo-se ao caráter biológico dos seres humanos, a segunda denotando os objetos produzidos materialmente pelo homem e que conformam o mundo e a terceira vinculada às diferenças entre indivíduos e entre sociedades (Magalhães, 2009). Essas dimensões da condição humana estariam vinculadas às atividades fundamentais do ser humano, o labor, a obra e a ação.O primeiro equivalente à vida biológica, o segundo ao mundo artificial dos objetos que o homem fabrica e o terceiro, o que "ocupava a posição mais elevada" "na medida em que (...) está ligado à esfera da política" (Arendt, 2017, p. 177), relativo à pluralidade entre os homens. Esses elementos configurariam a vida activa e se oporiam ao modo de vida contemplativa que, historicamente, teve a primazia no Pensamento Filosófico Ocidental.

Arendt (2017) defende que o homem enquanto animal laborans tornou o trabalho a condição da sua existência e foi aprisionado em seu ciclo vital e sujeito às necessidades do trabalho e do consumo. A redenção só seria possível mediante a capacidade do homo faber de fazer, fabricar e produzir aquilo que é durável. O homo faber, ao realizar suas obras, é senhor

\begin{tabular}{|l|l|l|l|l|}
\hline Qenista Dialactus & Ano 5 & n.13 & Agosto - Dezembro 2018 & p. $210-227$ \\
\hline
\end{tabular}


da matéria a ser modificada no processo de produção. Essa capacidade não se aplica ao animal laborans que está sujeito às necessidades de sua própria vida, nem ao homem de ação que depende dos seus semelhantes para agir. O homo faber, portanto, atenua a labuta do trabalho e ergue um mundo de durabilidade.

Se por um lado o homo faber é o senhor do processo de produção, por outro, ele só pode ser redimido do constrangimento da ausência de significado em um mundo marcado pela categoria de meios e fins mediante a produção de estórias significativas,o que ocorre pela ação e pelos discursos. A história (history) é o entrelaçamento dessas estórias (stories) humanas singulares que ocorrem, e, por meio da ação, que é a única atividade que se exerce diretamente entre homens e corresponde à condição humana da pluralidade, o homem se torna senhor de seus atos.

\begin{abstract}
A teia entre os homens precisa de muitos fios singulares que, ao serem tecidos, modificam seu 'colorido' constantemente. Sozinhos, esses fios estariam soltos; inserindo-se na teia comum, entrelaçam-se com outros e mais outros, de modo harmonioso ou conflitante. Com os encontros e desencontros - desenhos, rasgos e rasgaduras - surgem as histórias (stories) humanas que juntas forma a história (history). Cada fio, porém, ganha sua relevância somente na textura comum que, embora em constante transformação, existia antes de cada um deles e continuará depois(Almeida, 2009, p. 78).
\end{abstract}

Hannah Arendt argumenta que a ação possui uma dupla dimensão: a igualdade entre e a singularidadedos homens. A igualdade é exigida entre os homens na ação porque, caso não fossem iguais, estes não poderiam compreender uns aos outros no presente, nem mesmo captar as intenções dos atos perpetrados no passado por outros homens e muito menos elaborar o futuro. A unicidade, por sua vez, é necessária porque, caso os homens não fossem distintos, não necessitariam dos discursos para se fazer entender.

Cada ser humano nascido em uma comunidade é único e, quando está apto, adentra no espaço público se igualando aos demais. Ou seja, o nascimento pertence ao labor/trabalho e, só posteriormente, o homem nasce novamente se tornando um ser político. Isso faz com que cada nascimento seja um novo começo: "a ação, com todas as suas incertezas, é como um lembrete sempre presente de que os homens, embora tenham que morrer, não nasceram para morrer, mas para iniciar algo novo" (Arendt, 2005, p. 194). Por meio da ação, portanto, a renovação da humanidade é realizada de uma forma não prédeterminada. A ação pressupõe alteridade e é pelo discurso - pela palavra - que ela se revela. Assim, a ação só se faz possível no espaço público onde ocorre a teia das relações humanas. Essa teia de relações prossegue mesmo após a morte do homem de modo que ele nunca saberá

\begin{tabular}{|l|l|l|l|l|}
\hline Qenista Dialectus & Ano 5 & n.13 & Agosto - Dezembro 2018 & p. 210 - 227 \\
\hline
\end{tabular}


o resultado do seu agir: "o que importa aqui é perceber o agente que está se revelando, se mostrando em cada obra a qual, após sua morte, lhe garantirá imortalidade através da memória e da fala" (Silva, 2018, p. 78). Como diz Arendt (2017, p. 228):

\footnotetext{
Mas é também graças a esse meio, onde somente a ação é real, que ela produz estórias, intencionalmente ou não, com a mesma naturalidade com que a fabricação produz coisas tangíveis. Essas estórias podem, depois, ser registradas em documentos e monumentos.
}

Ao longo da história se manifesta a imprevisibilidade da ação humana que rompe com os processos até então estabelecidos. "Assim sendo, as ações humanas são ilimitadas, isto é, os seus contornos não são distintos ou cognoscíveis, pois imersos na teia de relações, não há como impor-lhes demarcações precisas ouprever seus resultados, como ocorre no trabalho" (Schio, 2009, p. 275). A ação ainda é composta pela instantaneidade e a evanescência. "A instantaneidade da ação ocorre pela rapidez com que ela pode ser produzida; a evanescência, pela característica que ela possui de dissipar-se, de desaparecer sob os olhos do próprio agente, após o seu início" (Schio, 2009, p. 276). Para Arendt, porém, a intenção da ação humana é superar essa fugacidade construindo, mantendo e controlando o mundo.

A imprevisibilidade e a irreversibilidade da ação não podem ser dissociadas, pois o que foi feito por meio da ação não pode ser desfeito. Ao contrário do homo faber que pode destruir o que produziu, a palavra dita ou o ato praticado em relação ao outro durante a atividade da ação não pode ser descartado.A irreversibilidade, ou incapacidade de se desfazer o que se fez embora não pudesse saber o que fazia, provoca um constrangimento que só pode ser redimido recorrendo a uma potencialidade da própria ação; a faculdade de perdoar. Em relação à imprevisibilidade, a incerteza do futuro, o remédio está na faculdade inerente ao homem de ação de prometer e cumprir promessas.

As duas faculdades do homem de ação - perdoar e prometer - formam um par. O perdão permite desfazer os erros do passado e o prometer instaura no futuro "ilhas de segurança sem as quais nem mesmo a continuidade seria possível nas relações entre os homens - para não mencionar todo tipo de durabilidade" (Arendt, 2017, p. 293). Ou seja, se não houvesse perdão, seríamos vítimas do nosso agir e impedidos de novas ações, como um "aprendiz de feiticeiro que não dispunha da fórmula para desfazer o feitiço" (Arendt, 2017, p. 293). As promessas, por sua vez, permitem conservar nossa identidade impedindo a falta de rumo e desamparo proveniente dos equívocos que cometemos. No perdão do outro e nas

\begin{tabular}{|l|l|l|l|l|}
\hline Qovista Qialectus & Ano 5 & n.13 & Agosto - Dezembro 2018 & p. $210-227$ \\
\hline
\end{tabular}


promessas realizadas e cumpridas a luz dissipa as trevas. Como ninguém pode se perdoar ou se sentir obrigado a cumprir uma promessa feita a si mesmo, perdoar e prometer dependem da pluralidade, da presença do outro.

Arendt afirma que foi Jesus de Nazaré e sua comunidade de seguidores os descobridores do papel do perdão nas questões humanas. Cristo sustenta, contra os escribas e fariseus e chocando seus contemporâneos que se perguntavam "quem é esse que também perdoa pecados?" (Lucas, 7, 49), que não é apenas Deus que tem o poder de perdoar (Lucas 5, 21-42; Mateus 9, 4-6; Marcos 7, 7-10). Não é Deus que perdoa, e sim os próprios homens que se perdoam antes de serem perdoados por Deus. Mais que imitar Deus cabe ao homem na mensagem de Cristo perdoar o outro homem no íntimo do coração, só assim Deus fará o mesmo. Essa concepção de perdão não se aplica mal radical.Esse tipo de mal é raro eDeus, segundo a visão cristã, se encarregará dele no Juízo Final caracterizado pela justa retribuição (Lucas, 16, 27). O mal banal decorrente das ofensas cotidianas que são parte das relações humanas, ao contrário, é passível de perdão contanto que o pecador não peque mais (Lucas 17, 3-4). Somente mediante a desobrigação gerada pelo perdão, o homem pode ser livre para recomeçar. Dito de outra maneira, o perdão é a única forma de reação que, além de reagir, age de novo e inesperadamente, libertando tanto aquele que perdoou como o que foi perdoado.

No Cristianismo, porém, só o amor tem o poder de perdoar. Arendt se afasta do caráter teológico do ato de perdoar da Teologia Cristã e adota uma conotação política para o termo. Ela afirma que o amor é uma ilusão dos poetas que transformam sua capacidade exclusiva de amar em experiência universal. O que o amor representa para os poetas tem como contrapartida o respeito no domínio mais amplo dos assuntos humanos. A pensadora acredita que o respeito, por ser concernente ao ser humano real e não a um poeta, é suficiente para que o perdão ocorra. Não fosse pela capacidade de perdoar, o ser humano estaria fadado a seguir automaticamente o curso inexorável do cotidiano ou se render ao desejo de vingança. O perdão interrompe esse curso que culminaria na destruição e ruína para iniciar algo novo. Talvez, por isso, Jesus compare o ato de perdoar a um milagre. O milagre que salva o mundo da sua ruína natural e permite os recomeços. Também se afastando do conceito de milagre de cunho teológico do cristianismo, Arendt encara o milagre como oriundo da capacidade humana de agir, rompendo processos e iniciando algo novo.

\section{Lévinas: humanismo e pluralidade}

Conceitos fronteiriços entre Filosofia e religião permeiam a obra de Lévinas $(1974,1991,1997,2000,2002)$ colocando em contato duas tradições aparentemente tão

\begin{tabular}{|l|l|l|l|l|}
\hline Qovista 2 Dialectus & Ano 5 & n.13 & Agosto - Dezembro 2018 & p. $210-227$ \\
\hline
\end{tabular}


diferentes: o Judaísmo como fonte de verdade e a Fenomenologia como modo de compreensão da realidade. Buscando fazer uma reflexão sobre a Filosofia e a Civilização Ocidental, Lévinas aproxima tanto o Judaísmo e a Filosofia que é impossível discernir seus elementos (Urabayen, 2005). Talvez por isso Derrida (apudVásques Moro, 1982, p. 87) afirme que sua obra é Filosofia sem sê-lo. A síntese dessas tradições é realizada pelo filósofo de duas maneiras: 1. De dentro da Filosofia ao fazer uma releitura da Fenomenologia de Husserl e Heidegger e defender que a ética deve ter o primado sobre a ontologia e 2. De fora da Filosofia para dentro da Filosofia, trazendo a contribuição da tradição judaica sobre a primazia da ética nas relações humanas.

A aproximação de Lévinas (1991) e Husserl (1979) ocorreu devido ao caráter hermenêutico da obra de ambos. Ao colocar a justificação de todo saber no sujeito, Husserl coloca em dúvida o transcendente e propõe o método fenomenológico. Esse método rompe com a dicotomia sujeito e objeto, pois é o método em que o sujeito toma consciência de algo produzindo sentido. Mas o que mais interessou a Lévinas, no entanto, não foi a Fenomenologia em si. O que lhe chamava atenção era a concepção husserliana da Filosofiacomo uma tarefa que deveria ser exercida livre de dogmas, de intuições caóticas e que permitia, principalmente, tratar a questão da ética. Para ele, a intencionalidade axiológica era fundamental em Husserl porque o caráter de valor provém da intencionalidade da consciência. O próprio Lévinas (1985) afirma que não seguiu as regras da Fenomenologia, pois não se sentia cativado pela redução fenomenológica que encarcerava o eu a si mesmo. Interessava a ele a noção de intencionalidade que permitiria responder a pergunta "onde estamos?" e poder, assim, tratar a questão da ética.

\footnotetext{
Esquece você da importância que tem para Husserl a intencionalidade axiológica [...] O caráter de valor não se adere a uns seres como consequência da modificação de um saber, senão que provém de uma atitude específica da consciência, de uma intencionalidade não teorética, irredutível de entrada ao conhecimento. Se encerra aí uma possiblidade husserliana que pode ser desenvolvida mais além do que o próprio Husserl disse sobre o problema ético e sobre a relação com o outro, que nele segue sendo representativa. [...] A relação com o outro pode ser investigada como intencionalidade irredutível, inclusive se se deve terminar por ver nisso a ruptura da intencionalidade. (Lévinas, 1991, p. 33, tradução do autor).
}

Assim como Lévinas, Heidegger (1974) questionava a Filosofia husserliana da subjetividade e buscava se instalar no contexto do mundano. Ao contrário de Husserl que concedia privilégios ao sujeito e à consciência, Heidegger propunha uma Fenomenologia que se baseasse na hermenêutica do ser no mundo. Para isso, ele promoveu uma destruição

\begin{tabular}{|l|l|l|l|l|}
\hline Qeovista Dialectus & Ano 5 & n.13 & Agosto - Dezembro 2018 & p. 210 - 227 \\
\hline
\end{tabular}


ontológica e defendeu a necessidade de se pensar o ser sob um fundamento diferente do que a Filosofia Ocidental havia pensado até então. Para ele o ser não era um ente e não podia ser pensado com tal, por isso ele coloca a questão do ser no horizonte de interpretação do tempo deixando de lado o ponto de vista psicológico. A ontologia fenomenológica heideggeriana afirma que o tempo é o único horizonte possível para compreensão do ser no mundo. É nesse sentido que ele afirma que o ser é uma realidade mundana (dasein).

Ao criticar a Fenomenologia de Husserl, que acreditava que poderíamos ser expectadores dos fenômenos, Heidegger promove uma radicalização ontológica da hermenêutica. Ele não acreditava que vida estivesse ante sim mesma como objeto o que impedia que ela fosse pensada por si mesma. A justificativa para isso era que o saber que tenho de mim não pode ser objetivado na medida em que a própria reflexão altera as vivências. Ao defender a premissa de que não existe uma posição neutra que permita pensar a vida sobre ela mesma, a hermenêutica Heideggeriana buscava compreender o saber préreflexivo, sem juízos prévios, deixando as coisas se mostrarem em si mesmas.

Lévinas (1991) enxerga em Heidegger a grande virtude de ter descoberto a verbalidade do ser em um período em que Filosofia tratava o ser como substantivo e não como verbo. Por outro lado, inspirado na tradição judaica e na crítica à ontologia da Filosofia Ocidental, acusava a manutenção do caráter ontológico do pensamento heideggeriano que permanecia sem um rosto humano. Para Lévinas, a Filosofia precisava enfrentar o problema do bem, do tempo e da relação com o outro. Ao contrário de Heidegger que compreendia o ser como abundância e generosidade, Lévinas (2000) afirmava que a inumana neutralidade do ser só poderia ser superada pelo surgimento no presente do sujeito como efeito da hipóstase.

\footnotetext{
Quando o indivíduo se dá conta de que nele há algo que ultrapassa a ontologia de seu sistema de referências, i.e., que os conceitos que o indivíduo tem sobre si mesmo não abarcam sua infinita singularidade, e busca nessa situação um novo sentido, a isso Lévinas chama de hipóstase. (...). Enfim, hipóstase ocorre quando o existente adquire seu próprio conceito, quando o existente adquire seu próprio existir. A hipóstase reintroduz o sujeito dentro da ontologia, da existência (Pimenta, 2012, p. $68)$.
}

Foi durante a Segunda Guerra Mundial que Lévinas desenvolveu a temática ética que culminará em sua nova visão do homem, ou seja, no humanismo do outro. A influência recebida do filósofo Martin Buber (1878-1965) acerca da questão da intersubjetividade já era, então, reconhecida por Lévinas (2002): a Filosofia do diálogo, o estudo da relação eu-tu como uma relação originária, a igualdade ou reciprocidade entre o eu e o tu, a insistência para que o

\begin{tabular}{|c|c|c|c|c|}
\hline Rovista Dialectus & Ano 5 & n. 13 & Agosto - Dezembro 2018 & p. $210-227$ \\
\hline
\end{tabular}


outro não apareça como objeto e o tratamento de Deus como o grande Tu. Tais aportes inspiraram Lévinas que, a partir do eu-tu buberiano (Buber, 1979), tentou ir além. Antes de se discutir o conceito face-a-face do filósofo Lituano é necessário, portanto, uma breve introdução ao pensamento de Buber em quem ele se inspira e dialoga.

A Filosofia do diálogo foi a essência das indagações e reflexões buberianas e o foco central de suas obras (Guinsburg, 1970). Buber defende na obra "Eu e Tu" (1979) que as atitudes que definem a existência humana frente ao mundo possuem uma dualidade que varia de acordo com a palavra-princípio proferida: as relações consideradas humanas são caracterizadas pela palavra-princípio eu-tu, as relações em que o outro é considerado objeto, pelo eu-isso. Na palavra-princípio eu-isso, o eu trata o mundo e as pessoas como objetos a serem manipulados. O eu da palavra-princípio eu-tu, por sua vez, gera um ato totalizador que promove uma visão de todo o ser. Buber percebe que o eu-isso era uma atitude frente ao mundo necessária ao estabelecimento das atividades sociais humanas, porém, ele aponta seu aspecto negativo quando ocorre a possibilidade de supressão das relações eu-tu nas relações humanas. Sua crítica à contemporaneidade é embasada na sobreposição das relações eu-isso sobre as relações eu-tu que estaria na origem do eclipse de Deus. O otimismo buberiano sugere, no entanto, que essa ocultação de Deus é sempre passageira. "Um eclipse do Sol é algo que tem lugar entre o Sol e nossos olhos, não no Sol mesmo" (Buber, 1995, p.48). Em sua finitude, o homem percebe o eclipse como a morte de Deus, mas é justamente nesses momentos que pode ocorrer a grande volta que Ele espera de nós. Transcendendo sua finitude e encontrando um sentido para vida, o homem pode reestabelecer sua relação dialógica com Deus que apenas aparentemente tinha morrido. Na verdade, as relações eu-tu são um antídoto à falta de significado gerado pela enganosa morte de Deus. É por meio da reciprocidade da relação eu-tu, do diálogo direto dotado de eticidade, que o Tu-Eterno se revela, permitindo que o homem, o mundo e Deus vivam em comunhão elevando as centelhas divinas.

O humanismo judaico de Martin Buber influenciou profundamente okehre (virada) do pensamento de Lévinas (Suscasas, 1998). Nas décadas de 1930 e 1940, ele aprofunda suas críticas à Filosofia Ocidental que se baseava na ontologia do ser, não levava em conta as diferenças entre os homens e não passava de puro pensamento e narcisismo (Lévinas, 1997). Segundo o filósofo, o ódio entre os homens refletia a crise do humanismo ocidental e sua resposta era o humanismo judaicoque privilegiava o perseguido em sua essência humana.Lévinas defendia que a neutralidade do ser se quebrava na relação com o outro e que a ética deveria ter primazia sobre a ontologia. Na assimetria das relações face-a-

\begin{tabular}{|c|c|c|c|c|}
\hline Rovista Dialectus & Ano 5 & n.13 & Agosto - Dezembro 2018 & p. $210-227$ \\
\hline
\end{tabular}


face abriam-se possibilidades de superação do self. Somente por meio dessa intersubjetividade assimétrica ocorreria uma transcendência em que o sujeito teria a possibilidade de não retornar fatalmente a si mesmo, de ser fecundo e, nas palavras do filósofo, "gerar um filho" (Lévinas, 2000, p. 165).

O face-a-face seria a única relação não violenta entre os seres humanos, pois implicaria em responsabilidade. O face-a-face é uma relação sem intermediários que permite ver a humanidade do outro em seu rosto e a Filosofia Ocidental, presa à identidade do ser e a impessoalidade, não compreende esse conceito. Somente pela hipóstase, o sujeito sente-se na obrigação frente ao outro. A ética consiste na aparição desse outro que é colocado em primeiro lugar, a ponto de se oferecer a própria vida por ele.

Ao longo de suas obras, Lévinas fez diversas críticas da Filosofia Ocidental a partir de suas raízes judaicas. Acusava essa concepção filosófica de tentar fazer uma síntese universal, de reduzir a experiência humana a uma totalidade onde a consciência abarcava o mundo. A esse totalitarismo da consciência, ele defende a alteridade do face-a-face que torna possível a subjetividade responsável e a construção de uma Filosofia fundada na ética. Suscasas (1998) afirma que essa subjetividade fundada na heteronímia de um sujeito descentrado é visível em diversos momentos da tradição judaica, como por exemplo na escuta obediente com a qual o judeu recebeu a Torá ou nas alianças que o povo estabeleceu com Deus.

Em síntese, Lévinas busca no sujeito descentrado a transcendência que se plasma na responsabilidade pelo outro. Essa transcendência no rosto do outro que se dá no âmbito da totalidade, mas que não se reduz a ela, pode ser expressa com o termo infinito. Tomar contato com o infinito não é uma experiência objetiva na medida em que o eu contém e se apresenta como recepção do outro. Não há, portanto, desvelamento no sentido Heideggeriano, e sim revelação. Essa relação com o infinito pensada, e estabelecida no face-a-face, adota as modalidade de bondade e justiça e torna a Filosofia de Lévinasuma oposição enérgica à neutralidade do ser e à totalidade, estabelecendo que a ética não apenas ser concebida como um ramo da Filosofia; ela é a "filosofia primeira" (Lévinas, 1997, p. 308)

\section{Arendt e Lévinas: por uma Filosofia do diálogo}

Os eventos da Segunda Guerra Mundial provocaram uma profunda crise no pensamento otimista do Iluminismo. A era moderna, que se inicia para Arendt com a Reforma Protestante, a invenção do telescópio e a descoberta da América (Almeida, 2009),foi marcada por um conjunto de valores que colocavam o homem como protagonista de sua história,

\begin{tabular}{|l|l|l|l|l|}
\hline Govista Dialectus & Ano 5 & n.13 & Agosto - Dezembro 2018 & p. $210-227$ \\
\hline
\end{tabular}


sempre em estado de autossuperação e autocompreensão (Gómes-Heras, 2008). O Iluminismo representa o apogeu desses valores originados no período renascentista. Os campos de concentração nazistas, por outro lado,podem ser entendidos como um contraponto à expectativa humana de construir uma sociedade que tivesse como mote esses ideais. As obras de Arendt e de Lévinas são respostas a essa crise civilizatória e buscam uma cura para esse “humanismo doente”(Gómes Caffarena et al., 1999, p. 61). Ambos criticam os rumos da Filosofia Ocidental ontológica e contemplativa e propõem um tipo de pensamento vinculado a uma abordagem dialógica. Suas ideias pertencem a um tipo de Filosofia utópica que"mira os céus com os pés assentados na terra" (Dias, 2004, p. 62), uma Filosofia realista que acredita na possibilidade concreta do processo de humanização.

As críticas à Heidegger são emblemáticas no pensamento de Arendt e Lévinas para a compreensão de suas contestações à Filosofia Ocidental. Lévinas questionava a Filosofia heideggeriana por não ter superado o nível ontológico e ter eliminado o rosto humano. Faltava a ele uma preocupação com a relação dialógica entre os indivíduos, pois se preocupava em demasia com a relação do indivíduo com seu próprio ser. Arendt, por sua vez, parte de fatos concretos, de eventos fáticos, para compreender o mundo, superando a ontologia heideggerianna que distorcia a realidade ao separar sujeito e objeto.

Ao restringir seu pensamento à inumana neutralidade do ser e seus atributos inatos de generosidade e abundância, Heidegger teria se equivocado. Lévinas defende que somente por meio da hipóstase, que ocorre no face-a-face, o sujeito sente-se na obrigação frente ao outro que é colocado em primeiro lugar, o que rompe a neutralidade do ser fazendo a ética assumir sua primazia sobre a ontologia. Faltaria a Heidegger, portanto, a valorização do caráter ético da relação interpessoal ao não conseguir se libertar da ontologia. Assim como Lévinas, Arendt rechaça a autarquia do ser humano ao reivindicar um tipo de humanismo que coloca enfatiza a ética da responsabilidade como resposta à crise da Civilização Europeia. Tomando a liberdade como capacidade exclusivamente humana, a autora afirma que ela passa a existir com o advento dos homens que agem e falam no mundo na esfera pública, daí o vínculo entre ação e liberdade no campo da política que permite o amor mundi. O homem possuiria para ela, além dos cinco sentidos que possibilitam a intuição dos objetos, um outro sentido que possibilita o compartilhamento do mundo com os demais, nos ajustacomunidade e é a condição de possibilidade de juízo. Utilizando a terceira máxima kantiana da "Critica da faculdade do juízo" (1993), § 40, a que afirma a possibilidade de um entendimento humano

\begin{tabular}{|c|c|c|c|c|}
\hline Rovista Dialectus & Ano 5 & n.13 & Agosto - Dezembro 2018 & p. $210-227$ \\
\hline
\end{tabular}


saudável, Arendt vislumbra a possibilidade de qualquer ser humano colocar-se no lugar do outro e julgar, mesmo que imaginativamente:

\footnotetext{
No sensus communis devemos incluir a ideia de um sentido comum a todos, isto é, de uma faculdade do juízo que, em sua reflexão, leva em conta (a priori) o modo de representação de todos os outros homens em pensamento, para, de certo modo, comparar seu juízo com a razão coletiva da humanidade (Kant, 1993apud Arendt, 2002, p. 379).
}

O desafio ao qual Arendt e Lévinas se propõem é colocar na cena da discussão filosófica a assimetria das relações face-a-face que, por serem intersubjetivas, se sustentam na autonomia humana que se apoia em uma suprema heteronomia. Isso fica explícito em Lévinas ao defender que mais do que uma relação ética formal e recíproca, as relações interpessoais são assimétricas e possuem uma ética substantiva que exige dar respostas ao sofrimento do outro. O conteúdo dessa relação face-a-face é o dar alguma coisa a alguém que necessita e o receber é o receber algo que foi dado em resposta a uma solicitação. Em Arendt, por sua vez, a questão da diferença entre os homens é explicitadana condição da pluralidade vinculada à atividade de ação. Quando homens diferentes se encontram por meio da ação e do discurso, eles dão significado ao mundo. Indo além de Lévinas, porém, a pensadora afirma uma dupla dimensão necessária à ação: a diferença e a igualdade entre os homens. Caso eles não fossem iguais, não haveria compreensão mútua. Sendo singulares na pluralidade, eles se igualam e se fazem compreender no espaço público iniciando algo inteiramente novo, renovando assim a humanidade.

A relação face-a-face, fundada na heteronímia e possível por meio dos discursos que fazem os envolvidos se compreender e se igualar, ocorre no ambiente mundano permitindo que o sujeito se torne um existente. Essa relação, mediada por atos de fala que recria a história humana, é sempre imprevisível e irreversível o que provoca a necessidade de redenção em momentos de constrangimento do outro. Daí a necessidade da faculdade de perdoar que é uma potencialidade da própria ação. O perdão, por sua vez, exige um novo começo que é garantido pela faculdade humana de prometer e cumprir promessas. Perdão e promessa só podem ocorrer na alteridade, na relação face-a-face que permite a hipóstase, momento em que o eu se sente na obrigação com o outro segundo Lévinas ou, na visão de Arendt, condicionada pelo respeito mútuo. Não fosse pelos rostos que se encontram na esfera pública e que se entendem por meio dos discursos, a vida não seria renovada e a humanidade estaria fadada a repetir o presente.

\begin{tabular}{|c|c|c|c|c|}
\hline Q Ronita Dialectus & Ano 5 & n.13 & Agosto - Dezembro 2018 & p. $210-227$ \\
\hline
\end{tabular}


É certo, porém, que a ação humana que se concretiza no face-a-face é sempre imprevisível e os resultados podem não ser, e muitas vezes não o são.O agir humano, portanto, possui uma complexidade que não pode ser compreendida pela Filosofia ontológica e contemplativa. É no contexto da ação que é possível compreender a importância do perdoar e prometer. A cada queda, os homens são capazes de renascer, pelo perdão e pelas promessas, dissipando as trevas e planejando o futuro. É assim que Arendt e Lévinas depositam uma fé profunda na capacidade humana de recomeçar.

Em síntese, as obras de Lévinas e Arendt são marcadas por uma crítica profunda à Tradição Filosófica Ocidental, ao seu caráter ontológico e ao seu anti-humanismo. É possível inferir de suas obras que essa Filosofia ontológica desencadeou uma racionalidade desmedida e autossuficiente que reflete e é refletida pela própria sociedade contemporânea alicerçada no isolamento, na competição, no consumismo e na indiferença. Sujeito apenas aos limites impostos pela própria consciência, o homem moderno se fechou em si, mesmo sacrificando a transcendência. Esse isolamento tornou o indivíduo facilmente seduzível por ideias totalitárias, seja na política ou na Filosofia. Sem capacidade de questionar, o indivíduo se torna homem da massa deixando de ser sujeito de sua própria história. Um tipo de homem que

\footnotetext{
age sem julgar, como se fosse um objeto ou um animal irracional submetido as regras institucionais, condicionado apenas pelo desejo de manter-se vivo e funcional, esse homem que não fala, que não intervém, que não se une, portanto, que não age politicamente (Aguiar, 2009, p. 245).
}

Enquanto a Civilização Ocidental e a Filosofia dela derivada criaram uma ética centrada na consciência do eu, Lévinas e Arendt propõem uma perspectiva dialógica de pensar o si mesmo a partir e com o outro. Afinal, a busca de uma sociedade justa exige a consciência da reciprocidade da responsabilidade entre o eu e o outro. Para alcançar esse objetivo, ambos defendem a revalorização do sentido ético do humano e o respeito às diferenças para a criação de uma sociedade assentada na pluralidade e na paz. Marcados pela experiência do genocídio nazista, esses pensadores revelam a indiferença do homem contemporâneo para com o outro e defendem a primazia da ética. Dessa maneira, o reconhecimento do outro representa uma possibilidade de se superar o self por meio da ética da alteridade. Esse seria o sentido da própria existência humana.

\section{Referências}

\begin{tabular}{|c|c|c|c|c|}
\hline Rovista Dialectus & Ano 5 & n.13 & Agosto - Dezembro 2018 & p. $210-227$ \\
\hline
\end{tabular}


AGUIAR, Odílio. Filosofia, Política e Ética em Hannah Arendt. Ijuí: Editora Unijuí, 2009. ALMEIDA, Vanessa Silvers de. Amor mundi e educação. Reflexões sobre o pensamento de Hannah Arendt. Tese de Doutorado. São Paulo, USP, Faculdade de Educação, 2009.

ARENDT, Hannah. Compreender: formação, exílio e totalitarismo. Belo Horizonte: Ed. UFMG, 2008a.

O conceito de amor em Santo Agostinho. Lisboa: Instituto Piaget, 1997.

(1958). A condição humana. 13 ${ }^{a}$ ed. Rio de Janeiro: Forense Universitária, 2017.

(1963). Eichmann em Jerusalém. Barcelona: DeBOLS!LLO, 2010.

.Homens em Tempos Sombrios. São Paulo: Companhia das Letras, 1987. (MDT)

. (1951). Origens do totalitarismo. São Paulo: Companhia das Letras, 2009.

. (1969). Sobre a violência. Rio de Janeiro: Civilização Brasileira, 2008.

(1963). Sobre a Revolução. São Paulo: Companhia das Letras, 2009.

Trabalho, obra e ação. In: Cadernos de ética filosófica, v. 7, n. 2, 2005, p. 175-201.

La tradidion cachée. Paris: Christian Bourgois Éditeur, 1996.

A vida do espírito. Rio de Janeiro: Relume-Dumará, 2002.

BARBOSA, Kherlley Caxias Batista. O confronto crítico entre Arendt e Heidegger. Perspectivas, vol. 2, n. 1, 2017, p.18-39

BUBER, Martin. Eu e Tu. $2^{\text {a }}$ ed. São Paulo: Cortez \& Moraes, 1979.

. (1952). Eclipse de Dios. México: Fondo de Cultura Económica, 1995.

MAGAlhães, Teresa Calvet de. Somos do mundo e não apenas no mundo. In: CORREIA, Adriano; NASCIMENTO, Mariângela (org.). Hannah Arendt - Entre o Passado e o Futuro Juiz de Fora: UFJF, 2009, p. 73-88.

DÍAZ, Carlos.El humanismo hebreo de Martin Buber. Salamanca: Ed. Mounier, 2004.

DUARTE, A. M.Hannah Arendt e o pensamento político sob o signo do Amor Mundi. In: BINGEMER, Maria Clara L.; YUNES, Eliane (org.). Mulheres de Palavra. São Paulo: Edições Loyola, 2003, p. 09-251.

GÓMES CAFFARENA, J.; MARIA MARDONES, J. Ateismo moderno: increencia ou indiferencia religiosa. México: Universidad Ibero-Americana, 1999.

GÓMEZ-HERAS, J. M. G. Un paseo por el laberinto: sobre política e religión en el diálogo entre civilizaciones. Madrid: Biblioteca Nueva, 2008.

GUINSBURG, Jacó. O judeu e a modernidade. São Paulo: Perspectiva, 1970.

HEIDEGGER, Martin.El ser y el tiempo. México: FCE, 1974.

HUSSERL, Edmund G. Meditaciones cartesianas. Madrid: Ediciones Paulinas, 1979.

KANT. Immanuel. Crítica da faculdade do juízo. Rio de Janeiro: Forense Universitária, 1993.

LAFER, Celso. Hannah Arendt: Pensamento, Persuasão E Poder. São Paulo: Paz e Terra, 1979.

LÉVINAS, E. Ética e infinito. Madrid: Visor, 1991.

\begin{tabular}{|l|l|l|l|l|}
\hline Q Ponista Dialectus & Ano 5 & n.13 & Agosto - Dezembro 2018 & p. $210-227$ \\
\hline
\end{tabular}


De la existencia ao existente. Madrid: Arena Libros, 2000.

Fuera del sujeto. Madrid: Caparrós Editores, 2002.

Humanismo delotrohombre. México: SigloVeintuno, 1974.

. De lo sagrado a lo santo. Cinco nuevaslecturas talmúdicas. Barcelona: Riopiedrasediciones, 1997.

MACHADO, Felipe D. A. Arendt e Schmitt. Diálogos sobre política. Belo Horizonte: Arraes editores, 2013.

PIMENTA, Leonardo G. Do ily a à hipóstase: a formação da consciência na teoria de Emanuel Lévinas. In: Revista da Faculdade Mineira de Direito, v.15, n. 29, jan./jun. 2012, p. 57-75.

SCHIO, Sônia Maria. A concepção arendtiana de ação humana, a partir de um fragmento de Antígona, de Sófo. In:ethic@, v. 8, n. 2, Dez. 2009, p. 271 - 289. p. $157-174$.

A ética da responsabilidade em Arendt e Jonas. In: Dissertatio, v. 32, n. 157, 2010, SILVA, Ricardo George de Araújo. Ação, pluralidade e política em Hannah Arendt. In:Argumentos, ano 10, n. 19, 2018, p. 73-86.

SUSCASAS, Alberto. Emmanuel Lévinas. Autoperceptión de un proceso historico. In: Antrophos, n. 176, 1998, p. 12-43.

URABAYEN, Julia. Las raíces del humanismo de Lévinas: el Judaísmo y la 227 Fenomenologia. Navarra: Ediciones Universidad de Navarra, 2005.

VÁSQUES MORO, U. El discurso sobre Dios em la obra de E. Lévinas. Madrid: publicaciones de la Universidad Pontificia Comillas, 1982.

\begin{tabular}{|c|c|c|c|c|}
\hline Qovista Dialectus & Ano 5 & n.13 & Agosto - Dezembro 2018 & p. $210-227$ \\
\hline
\end{tabular}

